فصلنامه گياهان دارويى

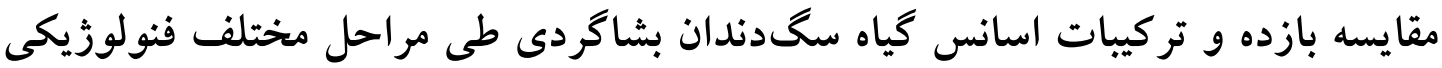

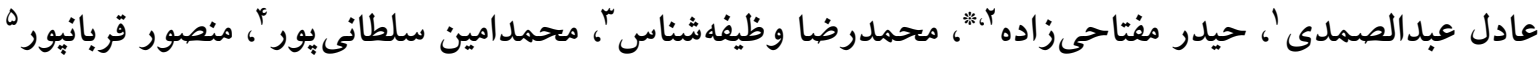

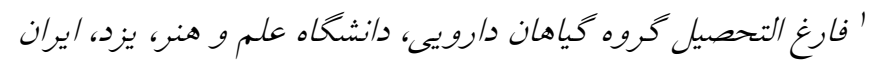

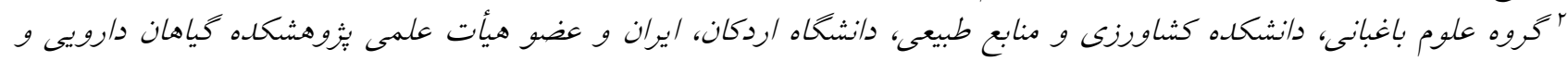

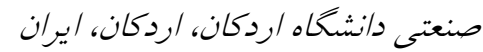
r بخش تحقيقات علوم زراعى و باغى، مركز تحقيقات و آموزش كثاورزى و و منابع طبيعى يزد، سازمان تحقيقات، آموزش و ترويج

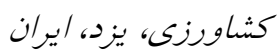

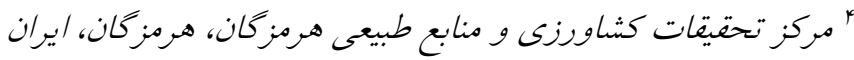

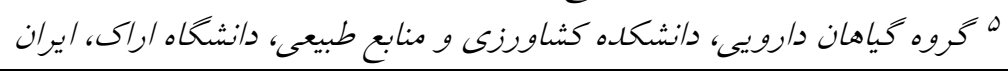
جكيده الطاعات مقاله

مقدمه: كياه سگُدندان بشاكردى (Pycnocycla bashgardiana Mozaffarian) از گونههاى اندميك دارويى

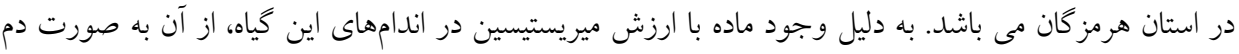
كلو إثزان:

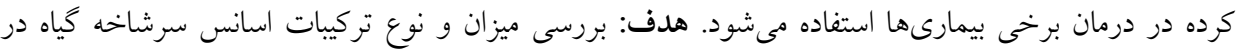

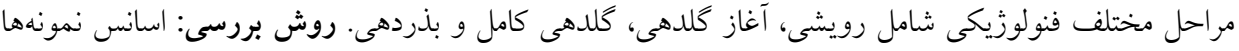

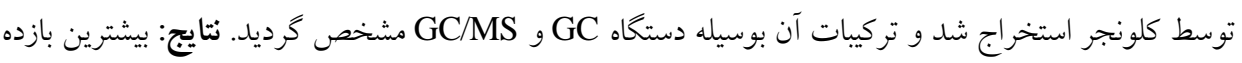

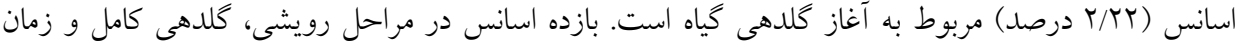

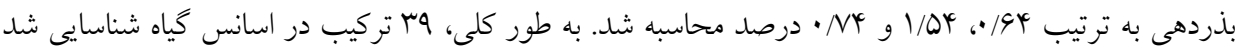

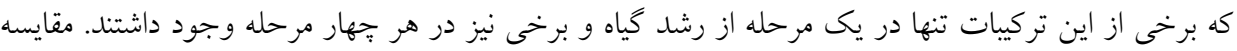
كياه سخ ميريستيسين كلدهى كروماتو گرافى كازى - جرمى إنى اندميك هرمز خان

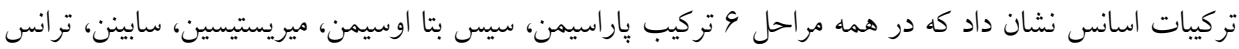

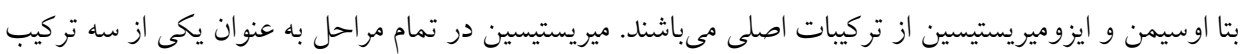

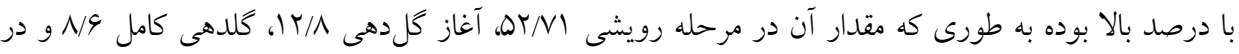

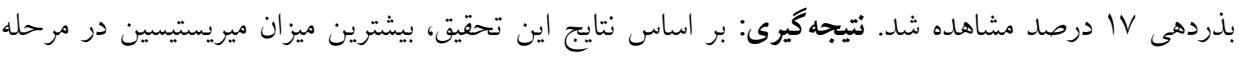

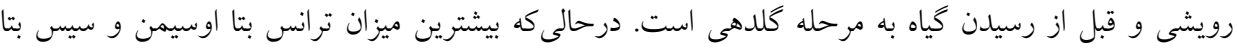

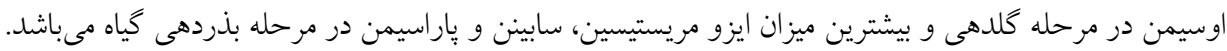

doi: $10.29252 /$ jmp. 19.75 .154

(C) 2020. Open access. This article is distributed under the terms of the Creative Commons Attribution-NonCommercial 4.0 International License (https://creativecommons.org/licenses/by-nc/4.0/) 
درصد اسانس را به خود اختصاص دادند [؟ب]. در آناليز

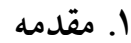

تركيبات اسانس نمونه كاشته شده اين گياه در استهبان،

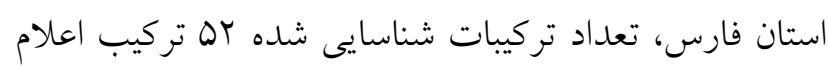

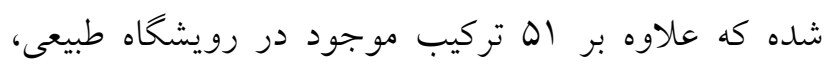

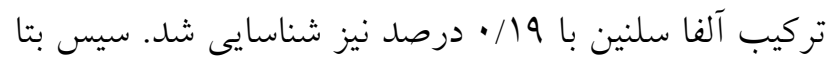

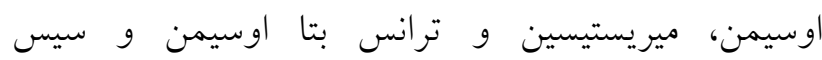
ايزومريستيسين به ترتيب، • •

درصد كزارش شدند [بأ. اسانس اين كياه اثرات ضدميكروبى قوى درات در برابر

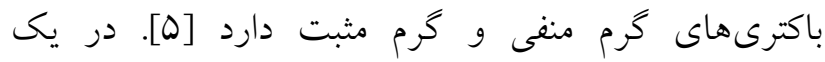

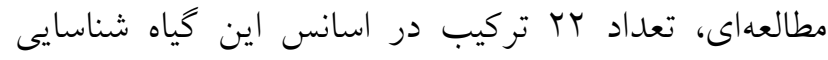

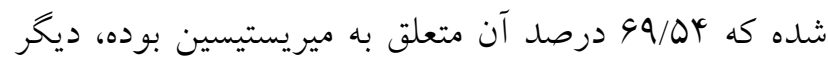

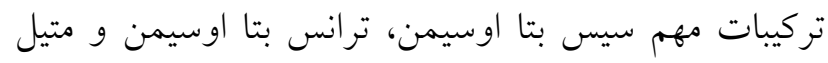

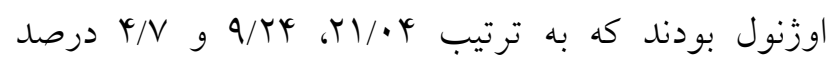
تركيبات را شامل شدند [ه].

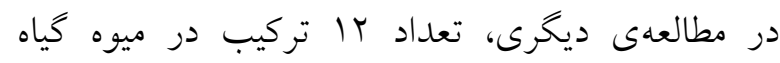

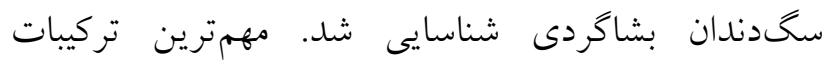

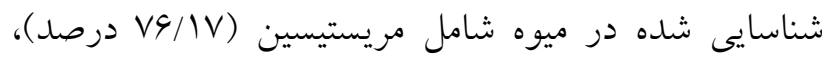

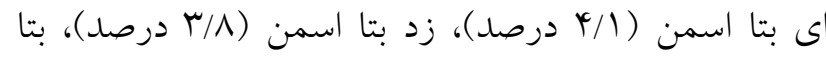

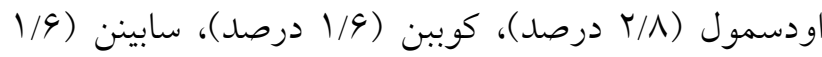

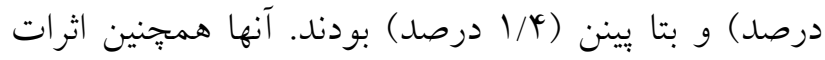

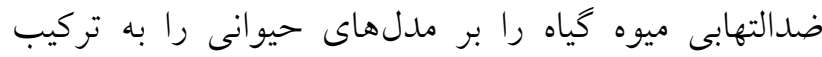

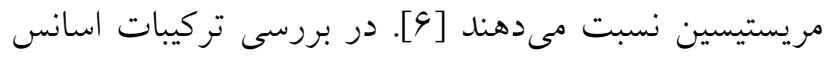

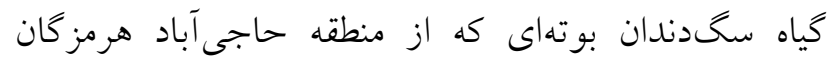

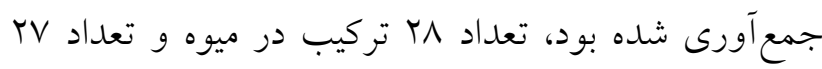

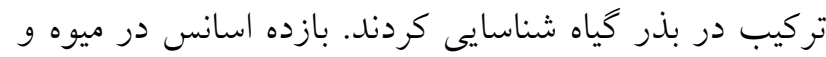

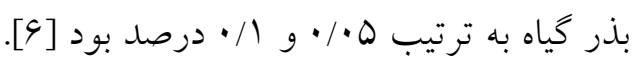
بيشترين مطالعات صورت كرفته به بررسى تركيبات

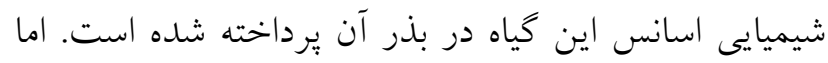

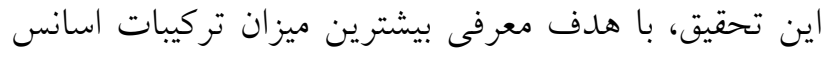

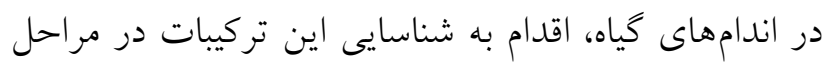

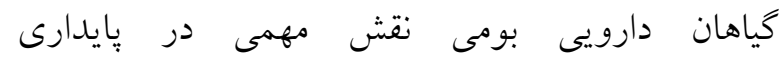

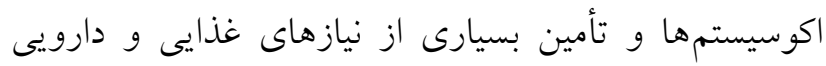

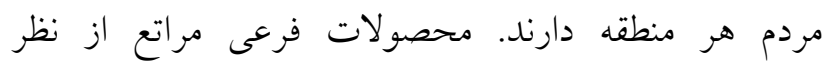

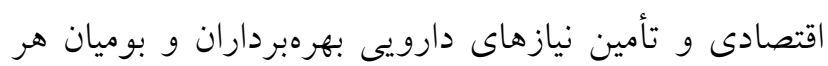

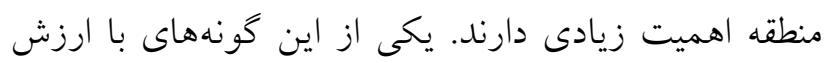

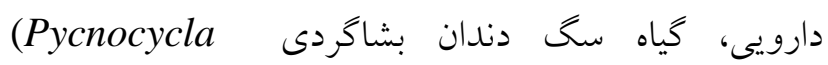

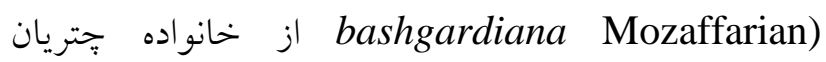
مىباشد كه از كونهاى دارويى مهم مناطق شرقى استان

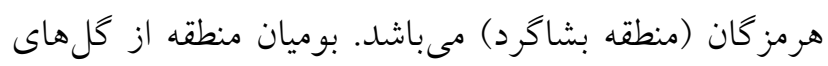

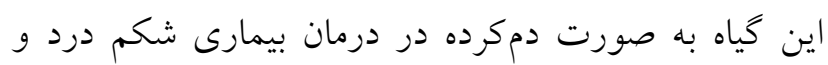
كليه استفاده مى كنند [ [1].

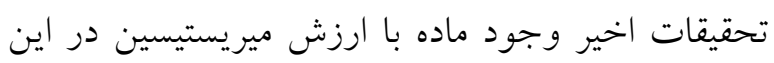

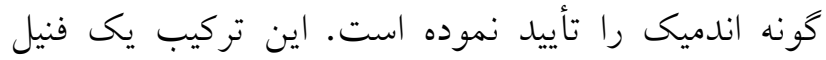

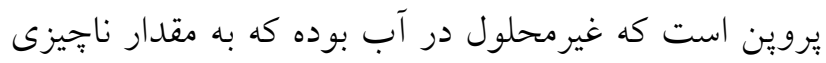

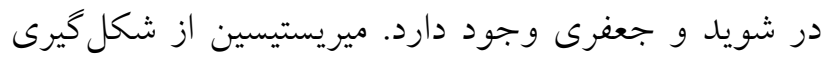

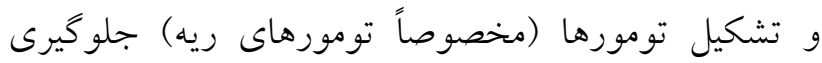

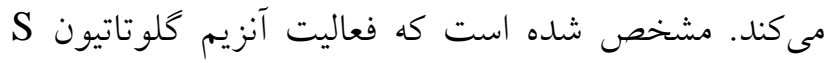

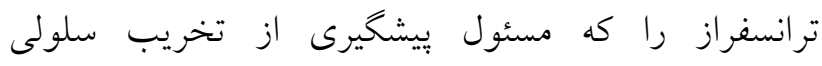

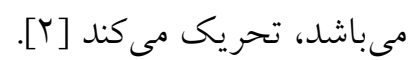
كياه سگدندان بشاگردى فعاليت ضدميكروبى قوى در بر برابر

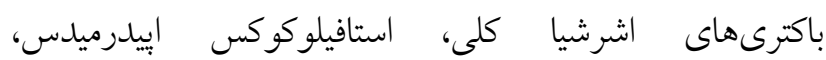

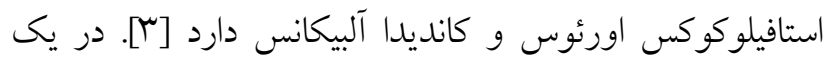
مطالعه، سب تركيب از اسانس اين كياه شناسايى شد كه تركيبات

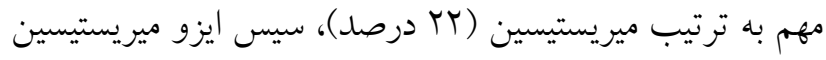

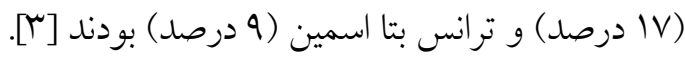
همجنين در بررسى تركيبات شيميايى اسانس كونه

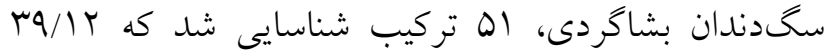

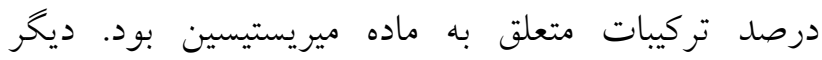

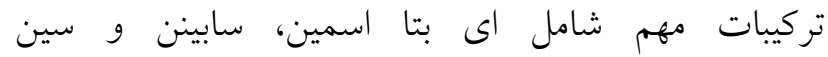
ايزوميريستيسين بودند كه به ترتيب r//9V، 
r.r. r. شناسا يیى تركيبهاى تشكيل دهنده /سانس

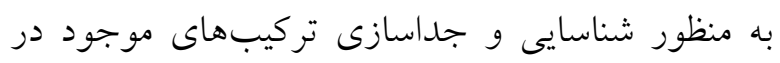
اسانس از دستخاه GC و GC/MS استفاده شد. دستخاه

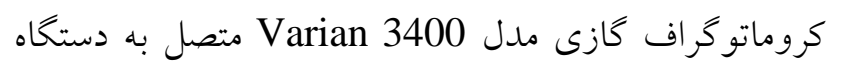

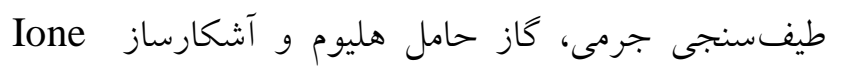

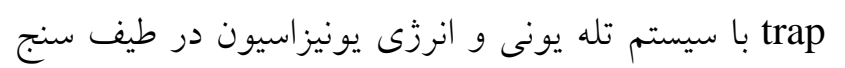

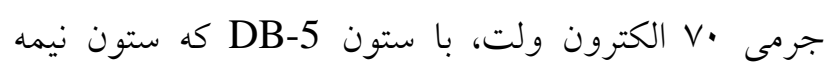

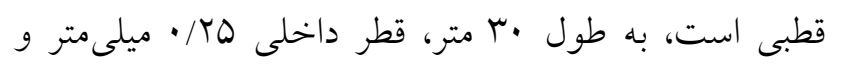

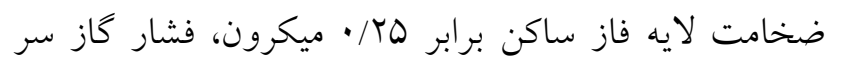

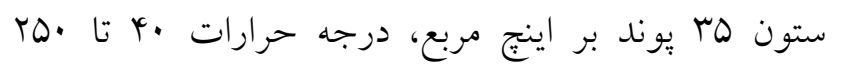

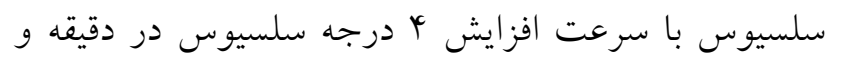

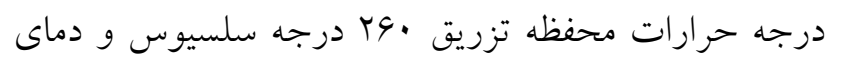

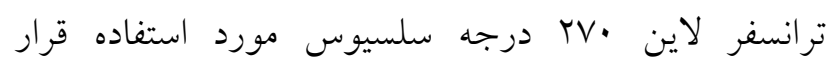

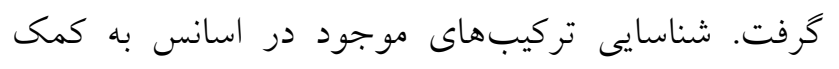

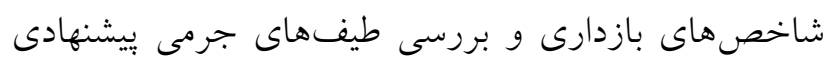

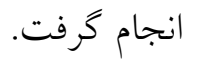

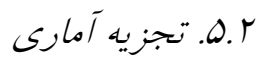

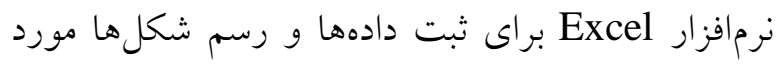

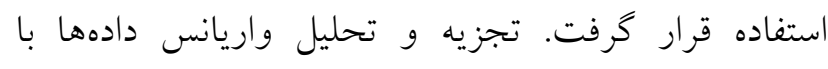

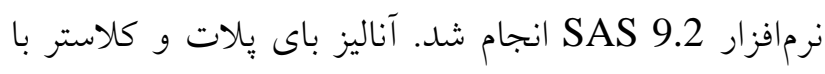
نرمافزار PAST انجام شد. همجنين، مقايسه ميانخين دادهها

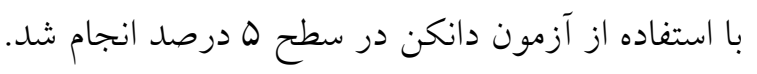

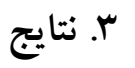
"r.ا. تغبيرات بازده اسانس كياه سخدندان بشاكردى در مراحل مختلف رشد نتايج تجزيه واريانس دادهها نشان داد كه بين مراحل مختلف رئل

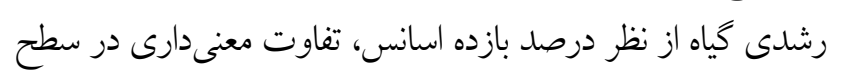

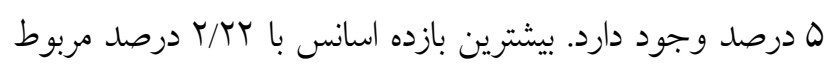

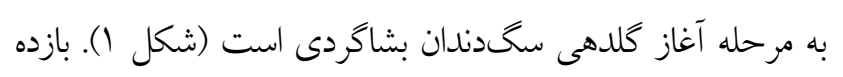

فنولوزيكى (رويشى، آغاز گلدهى، كلدهى كامل و بذردهى) شده است.

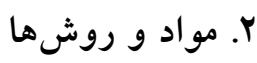

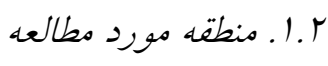

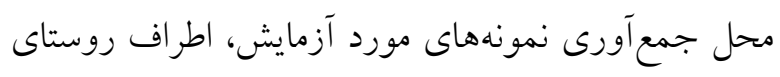

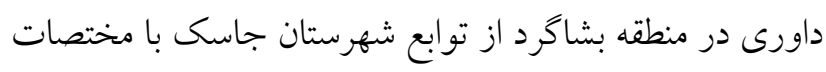

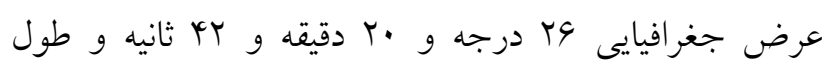

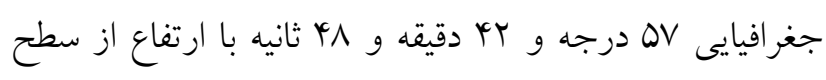

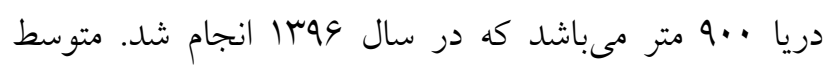

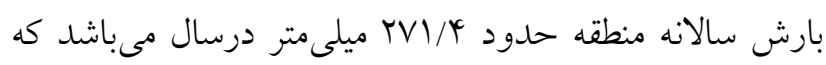

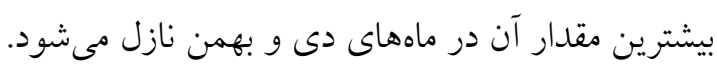

r.r. r. نمونه بردارى و آمادهسازى كياه براى /ستخراج اسانس

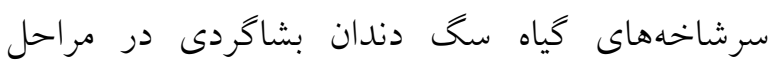

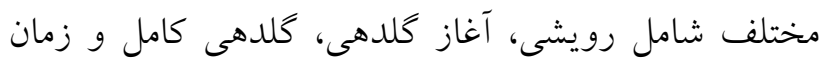

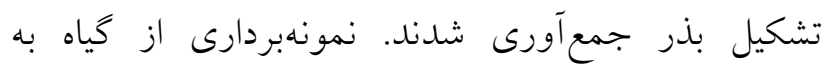

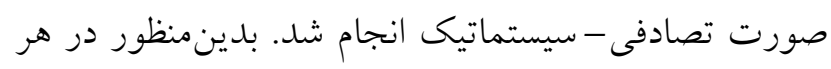

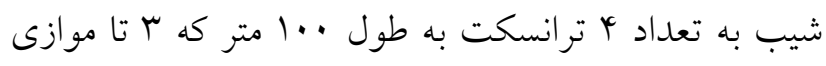

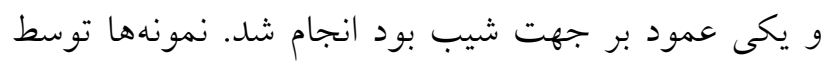

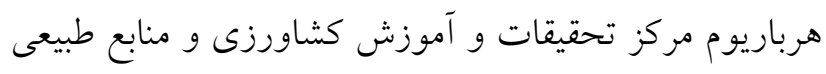

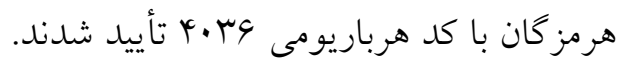

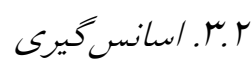
نمونهها يس از تميز كردن، در سايه و در دماى محيط،

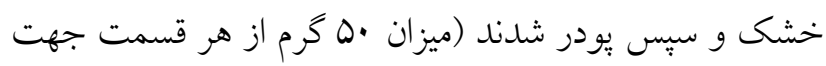

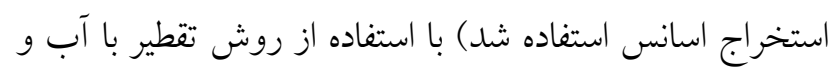

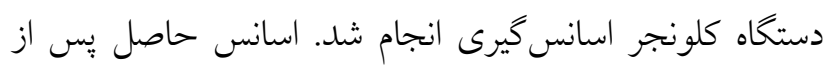

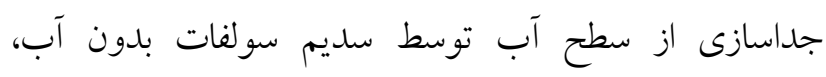

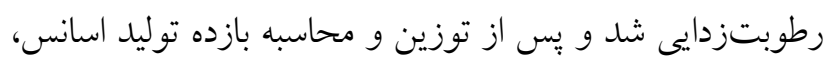

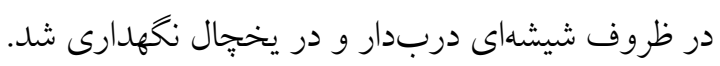




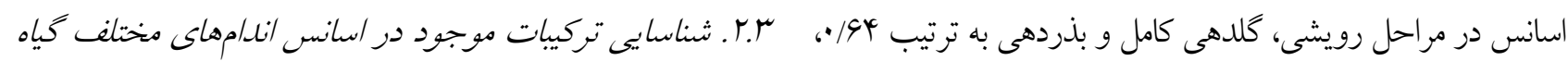

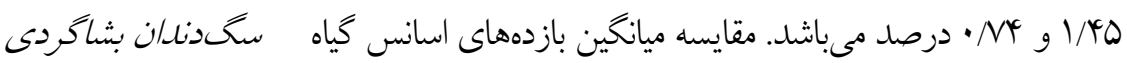

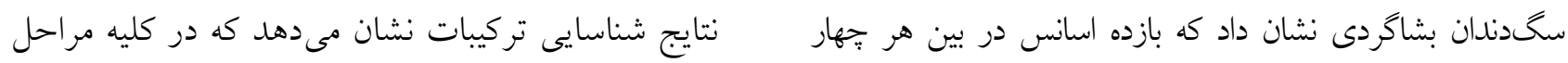

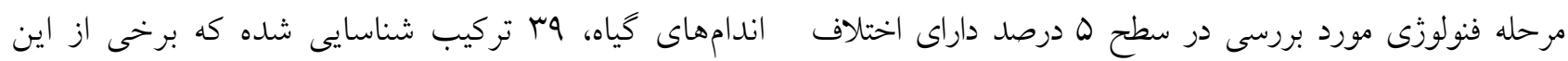

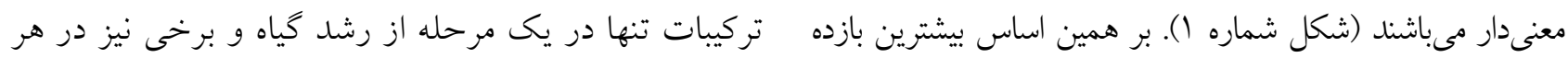

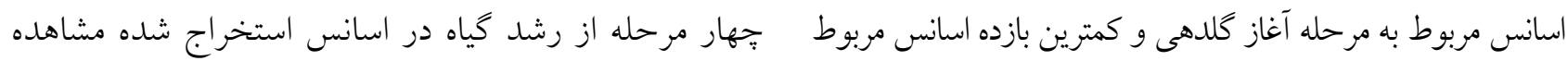

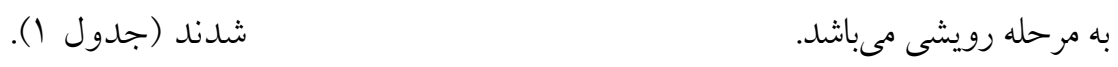

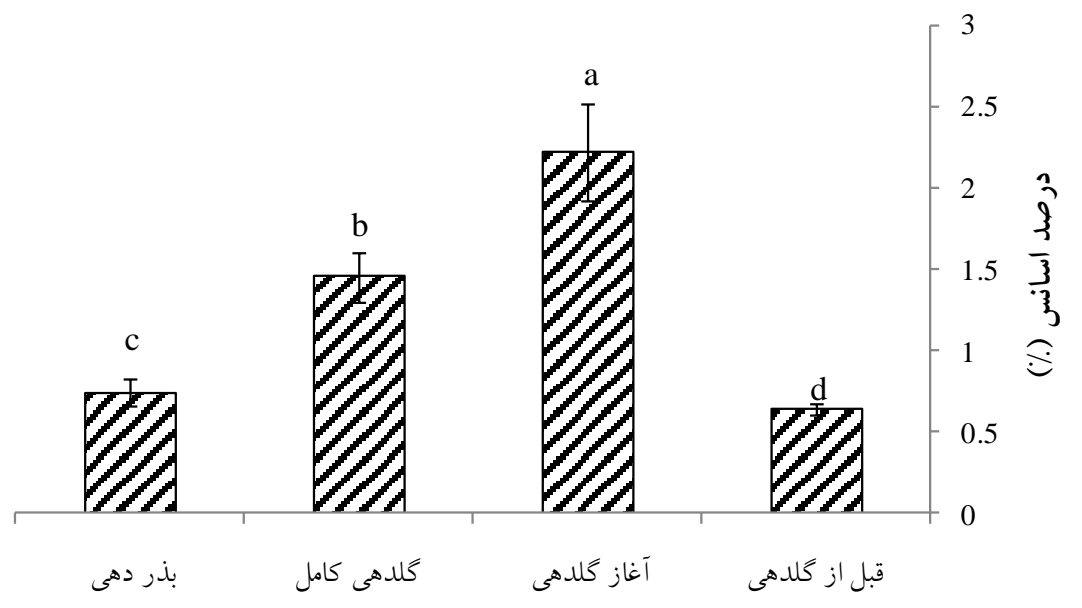

$$
\text { مراحل مختلف رشد }
$$

شكل 1. مقايسه ميانگين بازده اسانس (درصد) سرشاخههاى گياه سنگ دندان بشاكردى در مراحل مختلف رشد

\begin{tabular}{|c|c|c|c|c|c|}
\hline \multirow{2}{*}{ رديف } & \multirow{2}{*}{ تركيب } & \multicolumn{4}{|c|}{ درصد تركيب (درصد) } \\
\hline & & 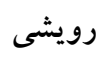 & آغاز كلدهى & كلدهى كامل & 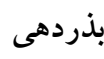 \\
\hline 1 & $\alpha$-Copaene & · & $\cdot / T \Delta S$ & · & . \\
\hline r & $\alpha$-Terpinene & . & . & . & . TK \\
\hline r & $\alpha$-Thujene & $\cdot / \Delta Q 1$ & . & $r / \wedge r$ & $\cdot$ / Ma \\
\hline r & $\alpha$-Alaskene & $1 / 4$. & . & - $190 \mathrm{r}$ & . \\
\hline 0 & $\alpha$-Eudesmol & $1 / \wedge$. & · & $1 / 919$ & · \\
\hline 4 & $\alpha$-Guaiene & $\cdot 10.1$ & - RYQ & $\cdot / 091$ & . NG9 \\
\hline v & $\alpha$-Gurjunene & · & . I A & · & · \\
\hline$\wedge$ & $\alpha$-Phellandrene & . & D & $r / \Delta \Lambda$ & $0 / 99$ \\
\hline 9 & $\alpha$-Pinene & $1 / \pi r$ & $1 / .40$ & - /Arq & $1 / 4 V$ \\
\hline
\end{tabular}

جدول ا. درصد تركيبات اسانس در مراحل مختلف فنولوزيكى كياه سخ دندان بشاكردى

IOV

فصلنامه گياهان دارويى 
ادامه جدول ا. درصد تركيبات اسانس در مراحل مختلف فنولوزيكى گياه سگ دندان (Pycnocycla bashgardiana mozaff)

\begin{tabular}{|c|c|c|c|c|c|}
\hline \multirow{2}{*}{ رديف } & \multirow{2}{*}{ 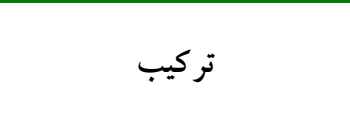 } & \multicolumn{4}{|c|}{ درصد تركيب (درصد) } \\
\hline & & رويشى & آغاز كلدهى & كلدهى كامل & بذردهى \\
\hline 1. & $\alpha$-Selinene & $1 / O V V$ & $\cdot$ & $1 / \pi 9$ & $\cdot$ \\
\hline 11 & $\alpha$-Ylangene & $\cdot M N V T$ & . & . & . \\
\hline ir & B-Elemene & $=/ 49$. & . & $1 / 1 \wedge$ & $\cdot$ \\
\hline ir & B-Eudesmol & 1/Arr & $\cdot$ & $\cdot / 19 \mathrm{~V}$ & I/.rt \\
\hline 14 & ß-Pinene &.$/ Q \% Q$ &.$/ 999$ & $\cdot$ & $1 / T r$ \\
\hline 10 & B-Selinene &.$/ 4 a r$ & $\cdot$ & $\cdot / 091$ & $\cdot$ \\
\hline 19 & Carvone &.$/ 4 m a$ & . & $\cdot$ & . \\
\hline iv & cis-Carveol & . $/$ VQS & . & . & . \\
\hline 11 & cis-Vertocitral & $\cdot / T V V$ & $\cdot$ & $\cdot$ & $\cdot$ \\
\hline 19 & delta-3-Carene & $\cdot / \pi \mu$ &.$/ 011$ &.$/ 4 M \mu$ & $1 / 11$ \\
\hline$r \cdot$ & $E-\beta$-(ocimene) & $11 / 0$ & $\Delta Y / M Y$ & $\cdot N H^{4}$ & $r / r \Delta$ \\
\hline ri & E-Caryophyllene & $1 / 911$ & $\cdot / \Delta Q T \mid$ & $1 / 4 \wedge$ & $1 / \cdot r r$ \\
\hline rr & $E$-Methyl isoeugenol & $1 / \cdot \Delta \Delta$ & · & $\cdot / 9 \mathrm{TV}$ & $\cdot$ \\
\hline rr & epi-Longipinanol &.$/ 410$ & . & $\cdot$ & $\cdot$ \\
\hline ry & Germacrene D & $\cdot / 00$ & $\cdot$ & $\cdot / \mu \varphi$ & · \\
\hline ro & Guaiol & $1 / 119$ & $\cdot$ & $\cdot$ & · \\
\hline rq & Humulene epoxide & $\cdot$ & $r / q 41$ & $r / v 1$ & $\cdot$ \\
\hline TV & Lavendulyl acetate & . & $\cdot \pi v$ & $\cdot$ &.$/ 911$ \\
\hline r^ & Isomyristicin & . & $r / 910$ & . & $14 / 9$ \\
\hline rq & Lavendulyl isovalerate & . & $1 / 914$ & . & $\cdot$ \\
\hline r. & Linalool butyrate & $\cdot$ & T/M & $\cdot$ & $\cdot$ \\
\hline щ & Limonene & $\cdot$ & $\cdot$ & $\mu / \mu$. & $\Delta / \Gamma \wedge$ \\
\hline rt & Methyl eugenol & $T / \cdot r V$ & 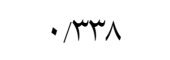 &.$/ 410$ & $\cdot$ \\
\hline r & Myrcene & ./194 & $1 / 914$ & $. / 4+4$ & $9 / 9 \mathrm{~V}$ \\
\hline re & Myristicin & QT/VQ & $1 T / V q$ & N/D৭V & $I V / 9 V$ \\
\hline ro & p-Cymene & $9 / \wedge 0$ & $\cdot$ & $N / \cdot \Delta r$ & $r \cdot / \Lambda$ \\
\hline re & Sabinene & $r / 9$. & $\cdot / 1 \cdot 1$ & $r \mid / 4$. & $r / 40$ \\
\hline rv & Spathulenol & $\cdot / M$ & $\cdot$ & $\cdot$ & $\cdot$ \\
\hline ґ & Terpinene-4-ol & . rar & $\cdot$ & $\cdot$ & $r / \Lambda \Lambda$ \\
\hline ra & $Z$-B(-ocimene) & $1 / \cdot V T$ & $|Y / 4|$ & ra/Ar & $1 / \mathrm{W}$ \\
\hline
\end{tabular}

تابستان 19V-1QY 


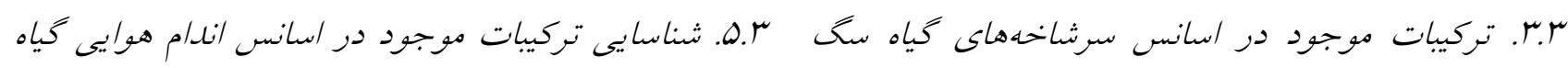
سخ دندان بشاكردى در مرحله كللهى كامل دندان بشاكردى در مرحله رويشى لريبر در اسانس بخش هوايى كياه سخ دندان بشاگردى در

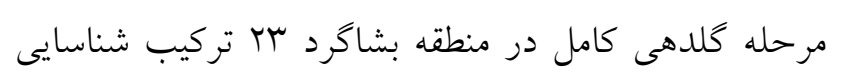

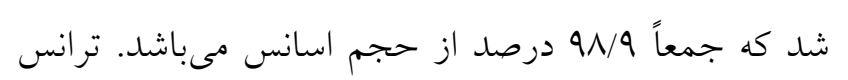

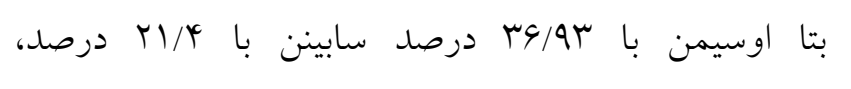

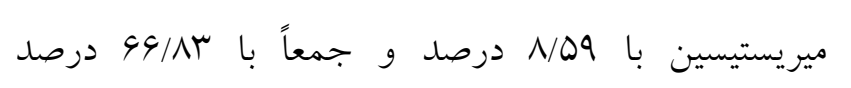
بيشترين تركيبات اسانس را تشكيل ميدهند. تركيبات ايخنول، متيل-دلتا-ترى كارن و ميرسين به ترتيب با هابع/•،

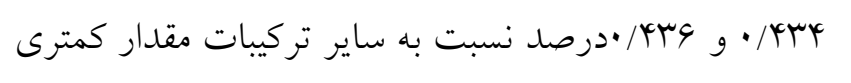

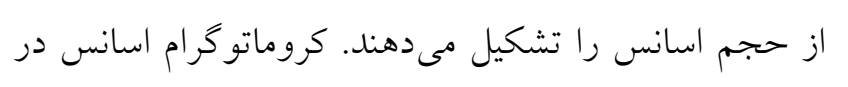
شكل لا نشان داده شده است. در اسانس بخش هوايى كياه سخدندان بشاكردى در مرحله رويشى در منطقه بشاكرد 94 تركيب شناسايى شد كه

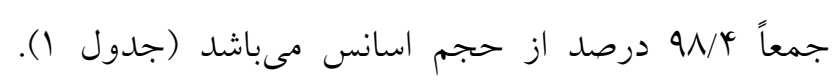

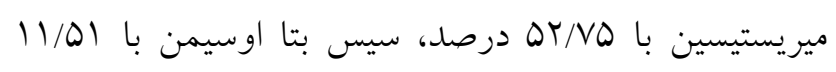

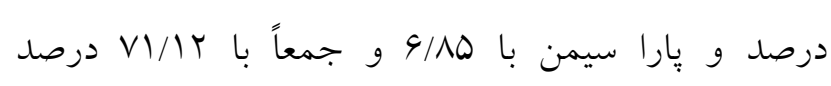
بيشترين تركيبات اسانس را تشكيل مىدهند. تركيبات دلتا-

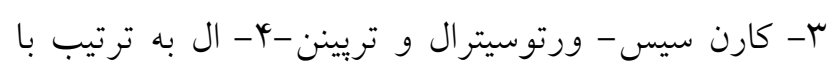

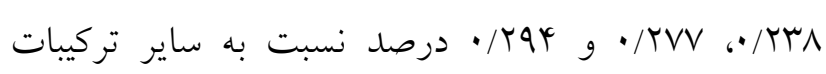
مقدار كمترى از محتواى اسانس را تشكيل مىدهند. كروماتو گرام اسانس در شكل r نشان داده شده است.

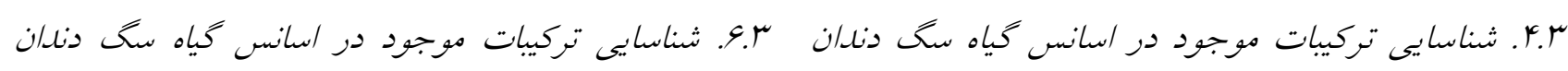

$$
\text { بشاكردى در مرحله بذردهى }
$$

بشاكردى در مرحله آغاز كللهیى

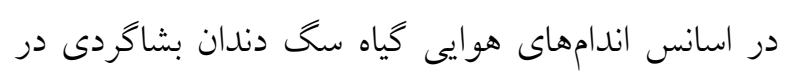

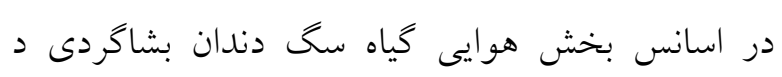
منطقه بشاكرد، 19 تركيب شناسايى شد كه جمعاً 99 درصد ازئ داه حجم اسانس مىباشد (جدول (). ياراسيمن با 99/•r درصد، 99/V مرحله آغاز كلدهى 19 تركيب شناسايى شد كه جمعاً درصد از حجم اسانس مىباشد (جدول ()). سيس بتا

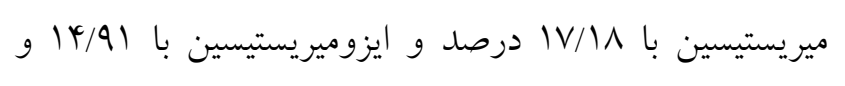

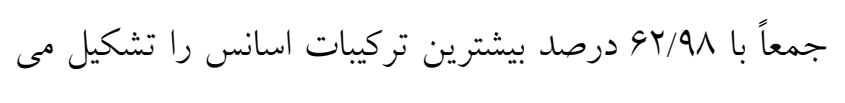

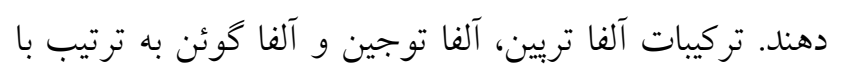

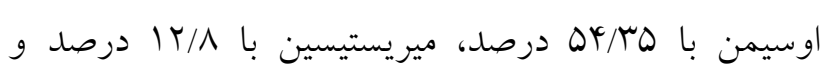
ترانس بتا اوسيمن با ع/ ا و و جمعاً با V9/9 درصد بيشترين

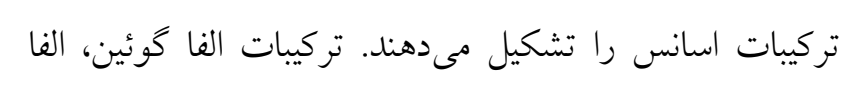

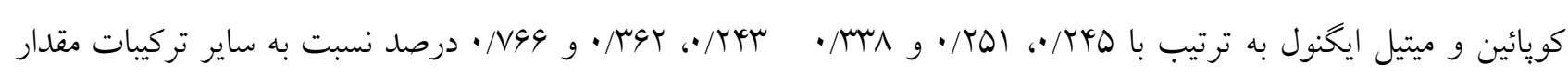
درصد نسبت به ساير تركيبات مقدار كمترى از حجم اسانس را ممترى از حجم اسانس را تشكيل مىدهند. كروماتوكرام تشكيل مى دهند. كروماتوكرام اسانس در شكل ب نشان داده اسانس در شكل ه نشان داده شده است. شده است. 


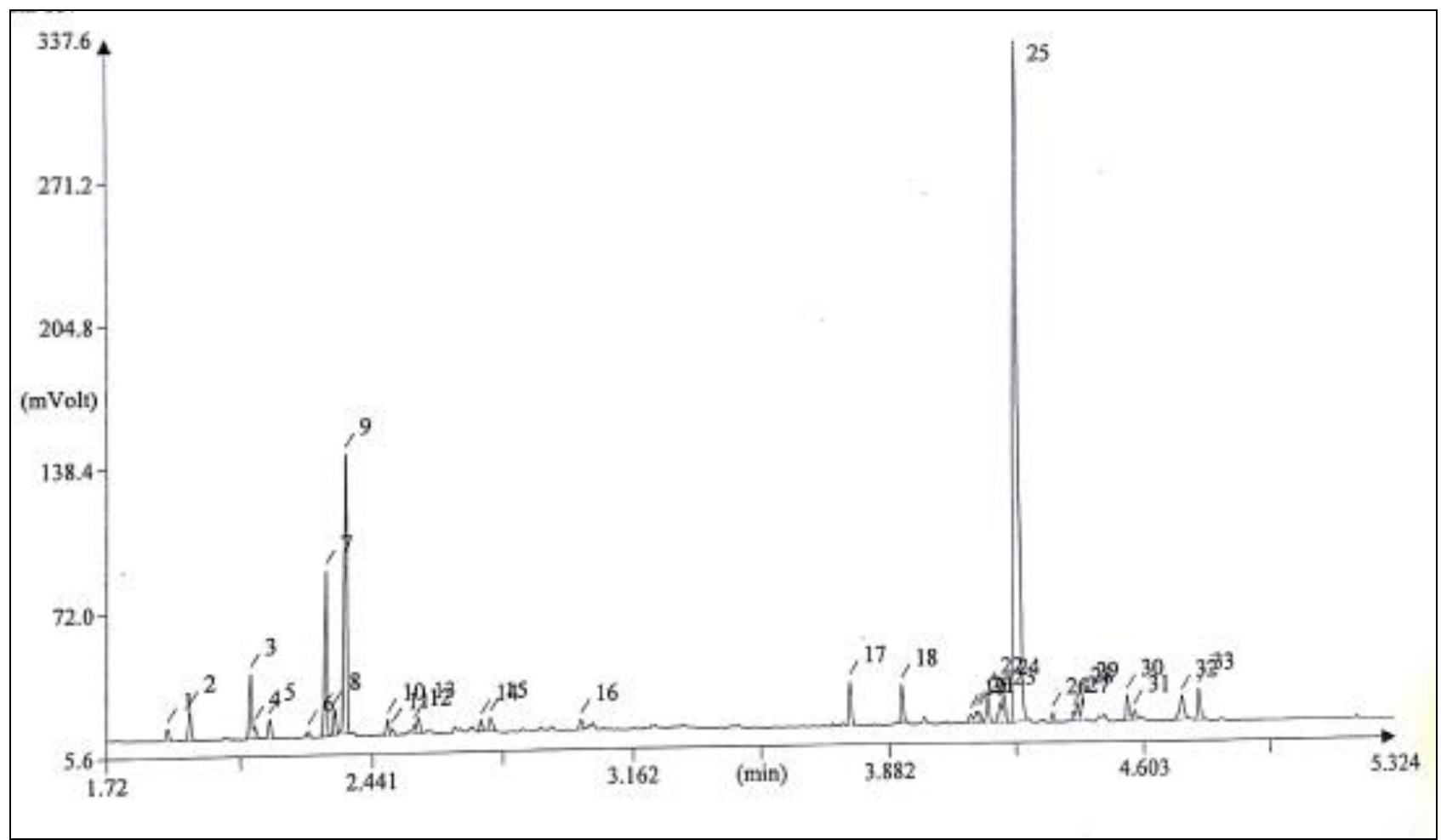

شكل r. كروماتو گرام اسانس سرشاخههاى گياه سگ دندان بشاكردى در مرحله رويشى

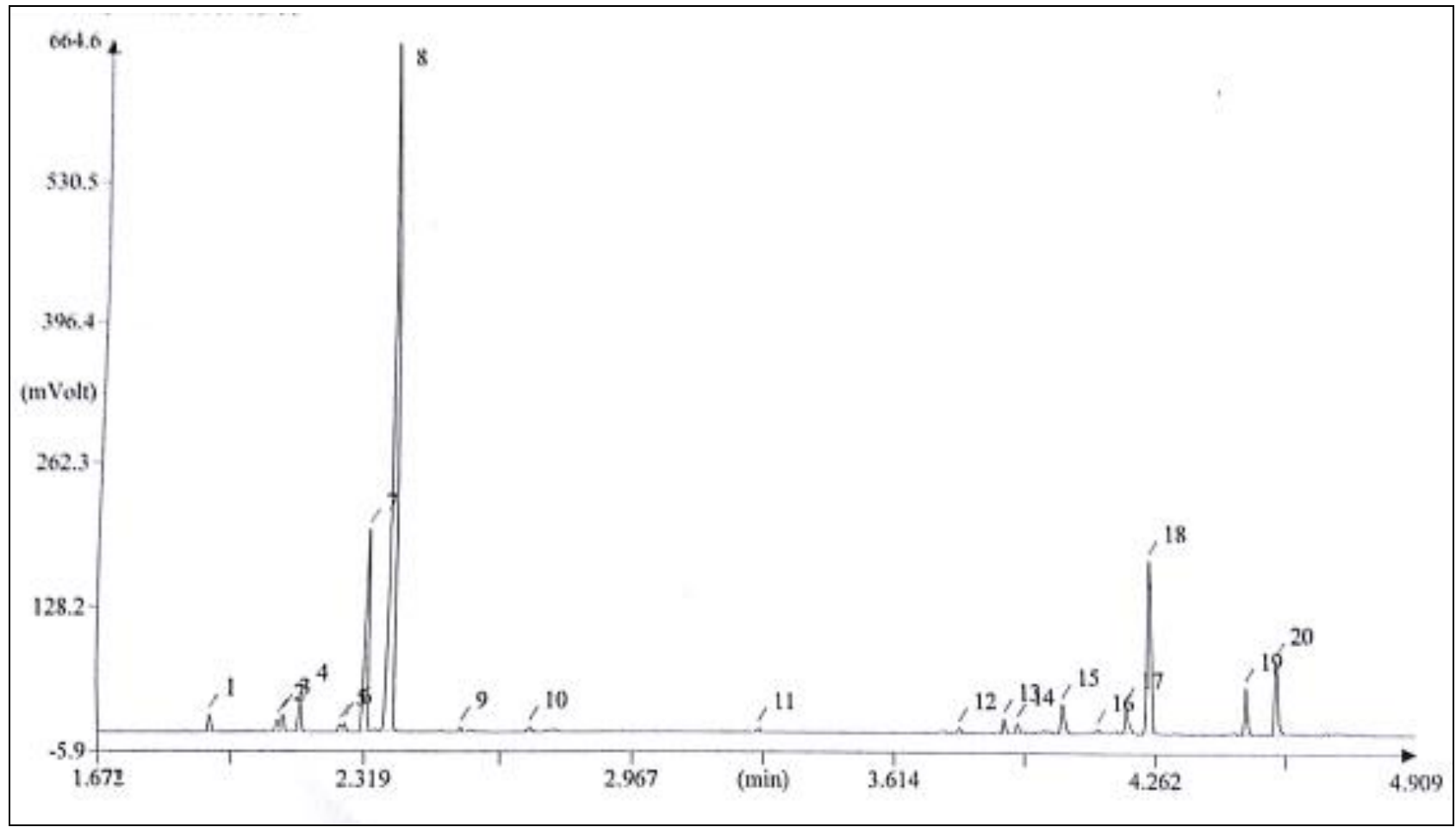

شكل r. كروماتوكرام اسانس كَاه سگ دندان بشاكُردى در مرحله آغاز كلدهى

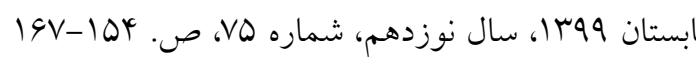

19.

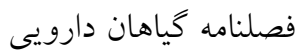




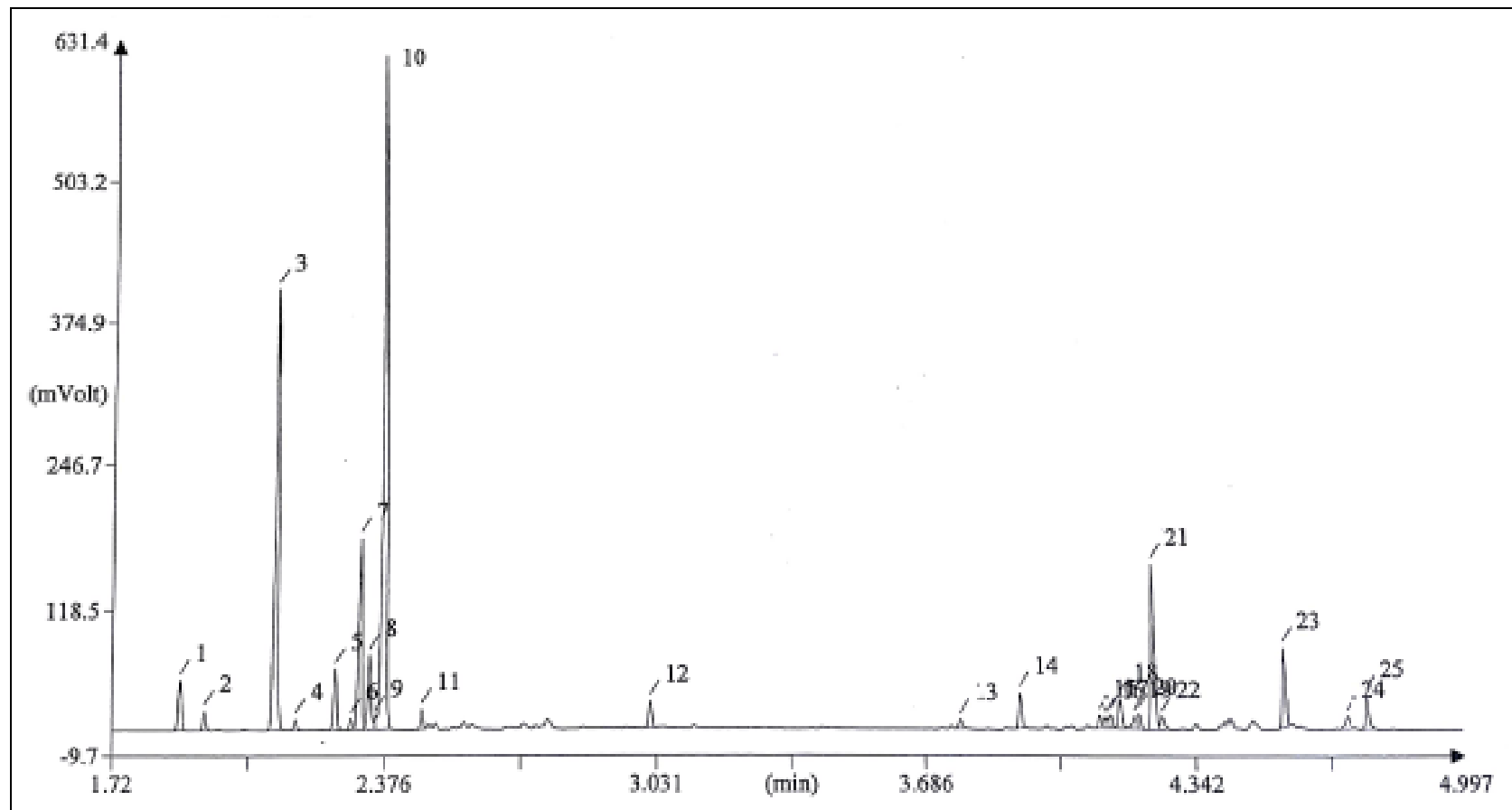

شكل ז. كروماتو گرام اسانس سرشاخه كياه سگ دندان بشاكردى در مرحله كلدهى كامل

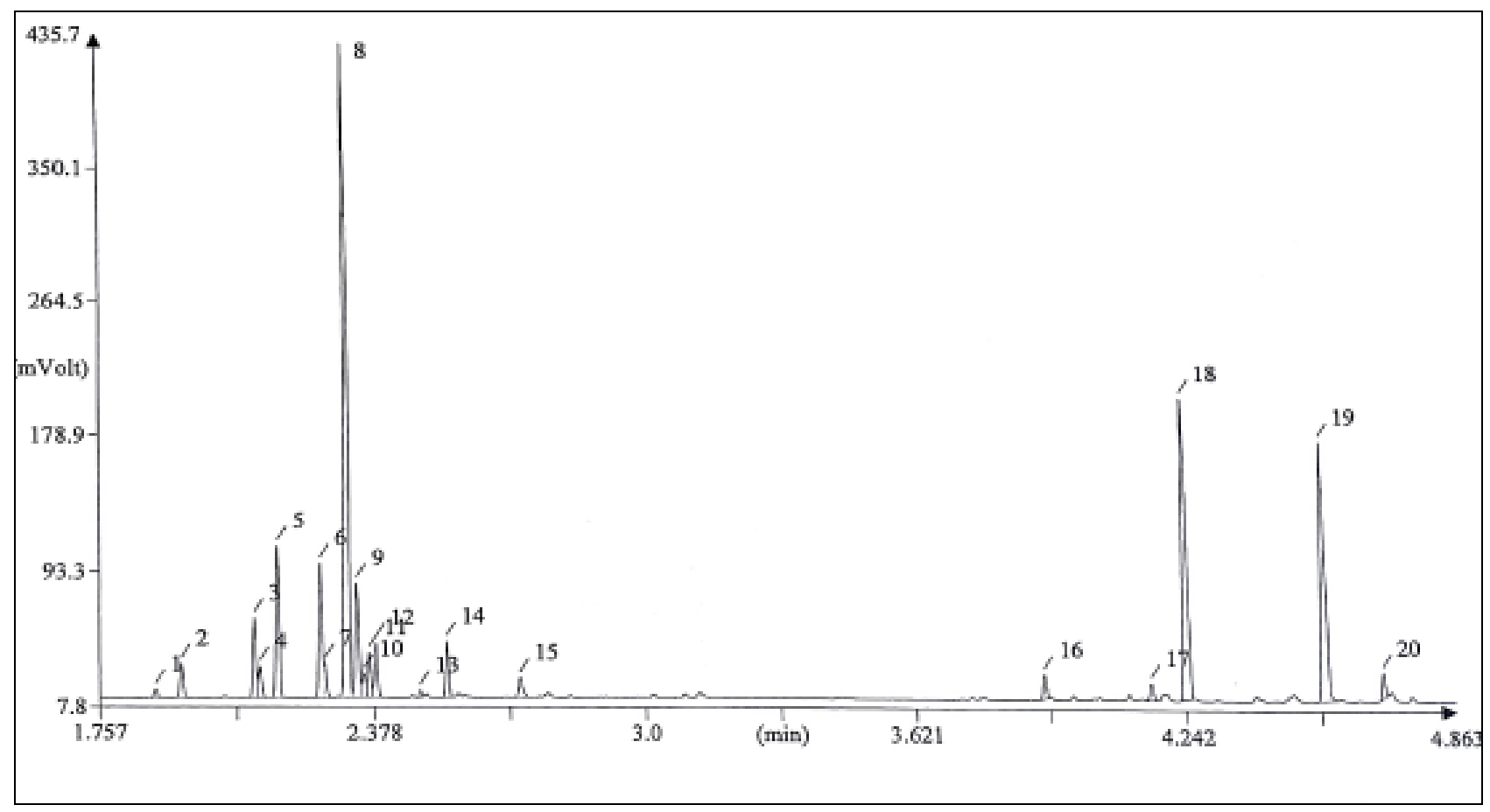

شكل ه. كروماتو گرام اسانس گياه سخى دندان بشاكردى در مرحله بذردهى

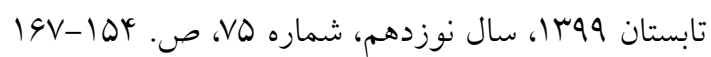


بررسى نتايج در قالب آناليزهاى آمارى شامل باى بِلات

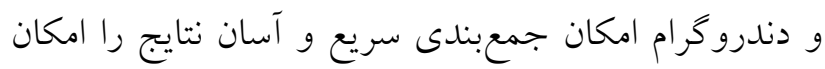

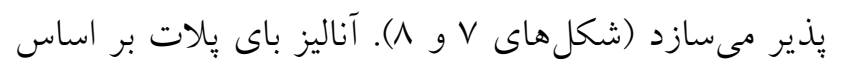

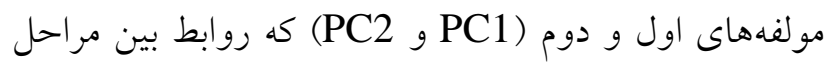
مختلف رشد را از نظر تركيبات اسانس نشان مى مدهد، انجام

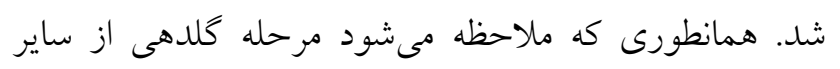

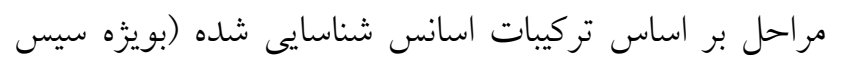

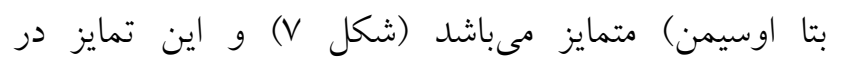

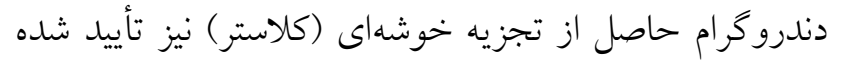

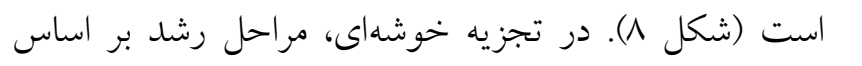

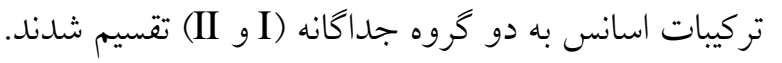

r.r. متايسه تركيبات /صلى /سانس در مراحل مختلف رشد كياه سگ دندان بشاكردى

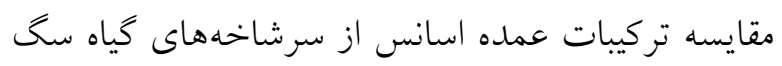

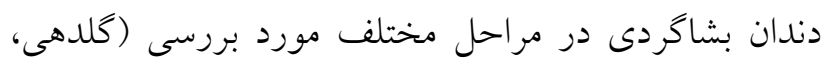

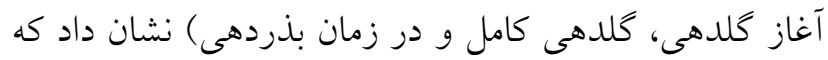

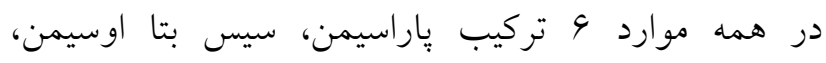

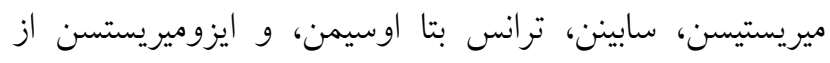

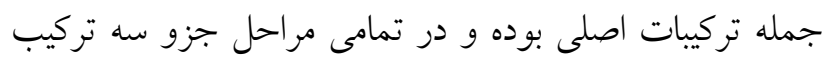
برتر مىباشند (شكل 9). تركيب ميريستيسين در هر جهار مرحله

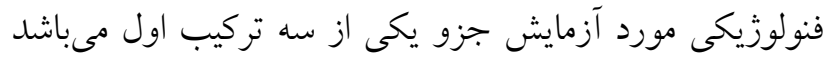

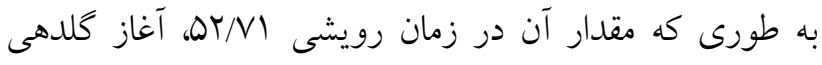

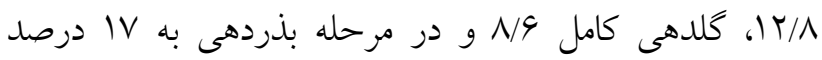

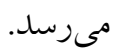

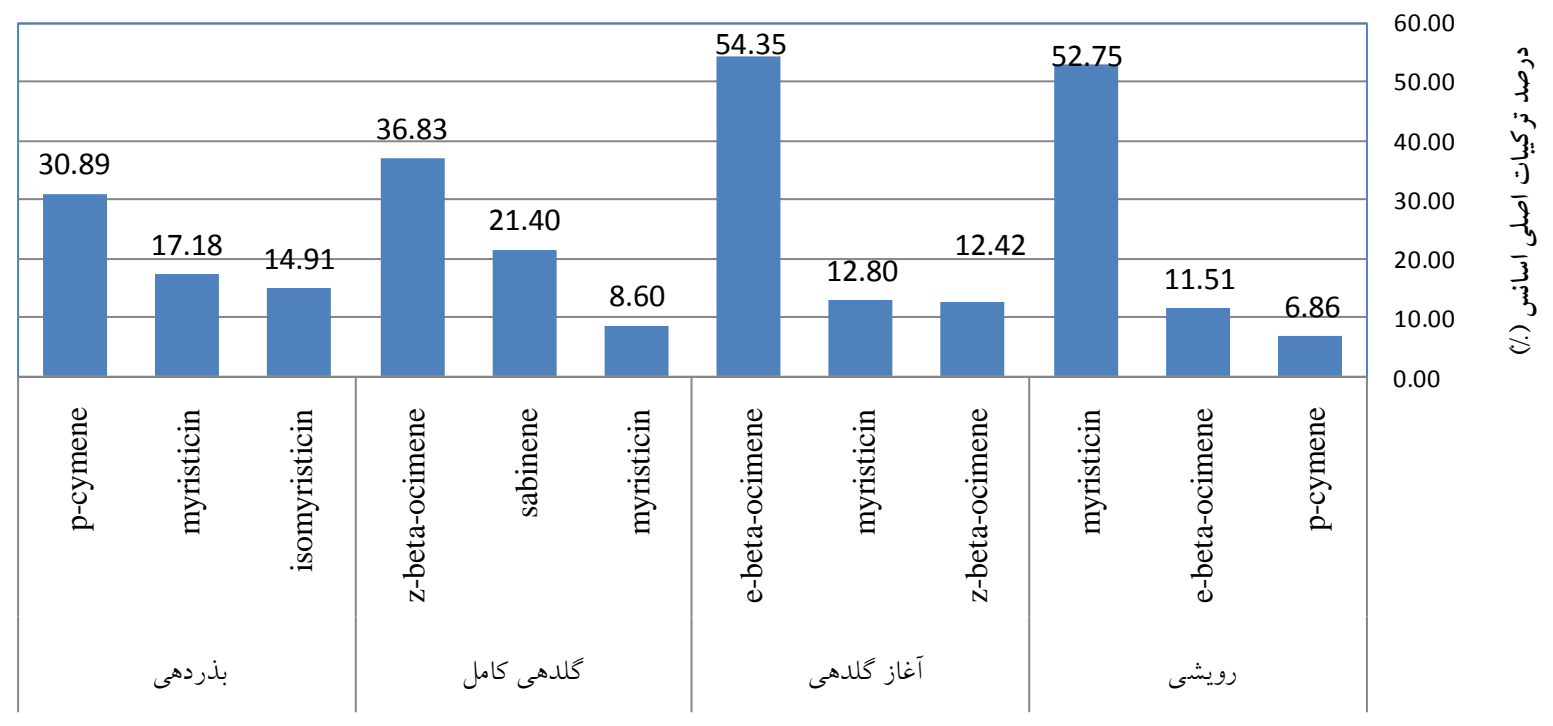

مر احل مختلف رشد

شكل 9. مقايسه تركيبات اصلى اسانس در مراحل مختلف رشد كَاه سگ دندان بشاكردى 


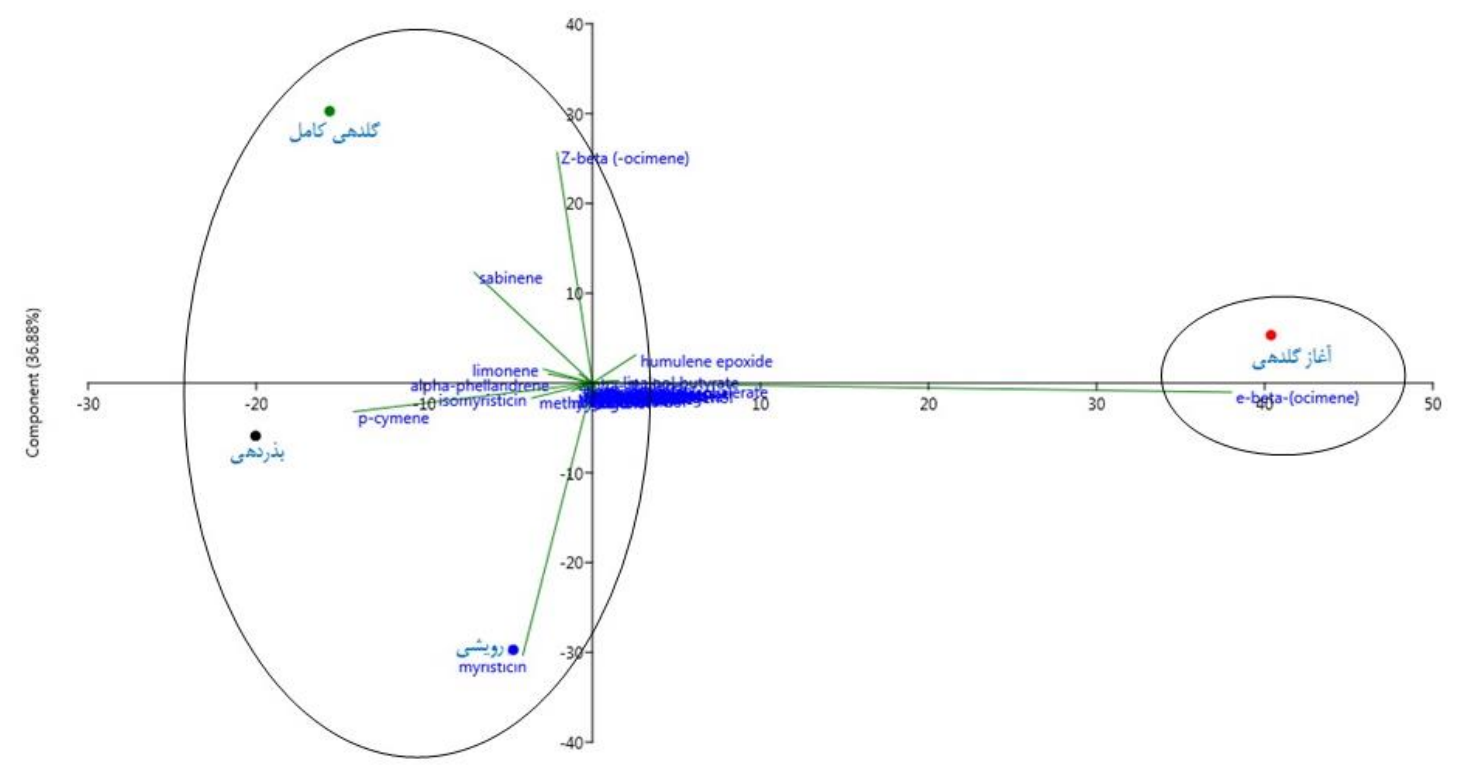

شكل V. نتايج آناليز باى يلات تركيبات مختلف اسانس كياه سنگ دندان بشاكردى در مراحل مختلف رشد

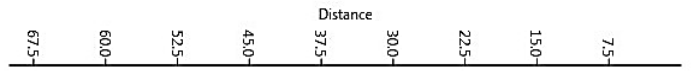

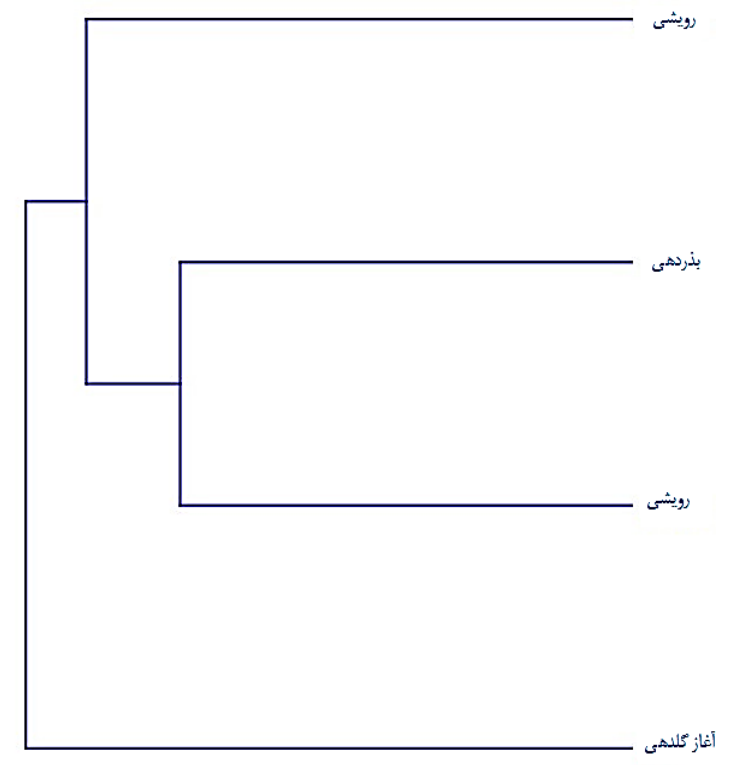

شكل ه. دندروكرام حاصل از تجزيه كلاستر تركيبات مختلف اسانس كَياه سنگ دندان بشاكردى در مراحل مختلف رشد با بهرهيرى از آلكوريتم UPGMA 
تركيبات اسانس كياه Pycnocycla bashagardiana در

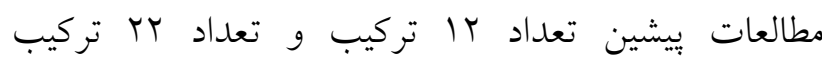

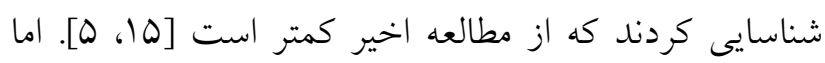

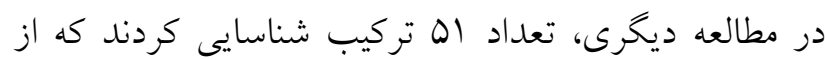

مطالعه اخير بيشتر است [ب]. درخصوص مقدار و نوع تركيبات اسانس، نتايج نشان

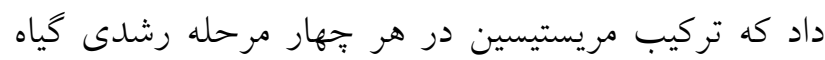

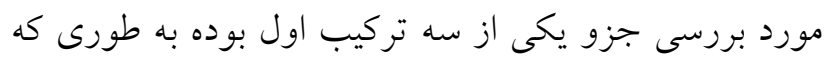

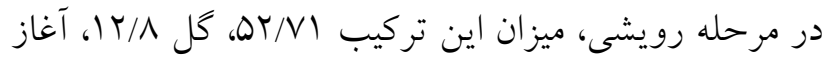

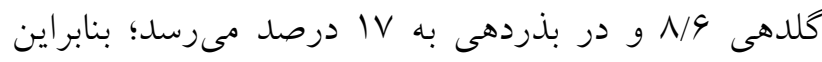

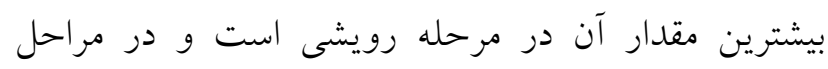

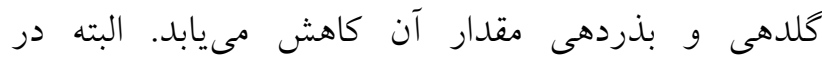

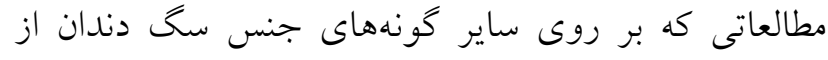

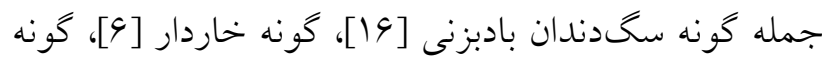

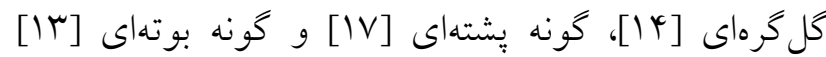

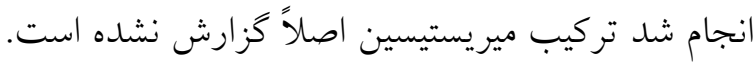
سيس بتا اوسيمن از ديخر تركيبات مهم كونه سخدئد فئدان

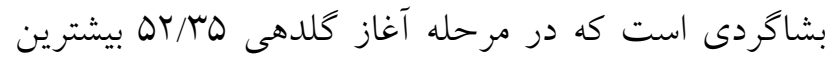

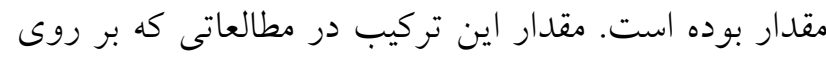

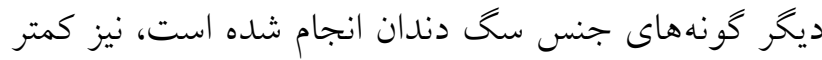

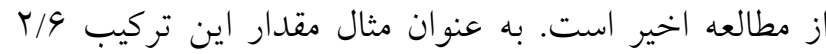

درصد كزارش شده كه از مطالعه اخير كمتر است بـ [9].

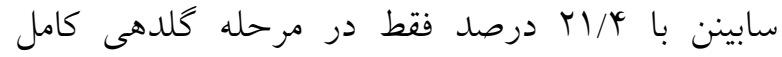

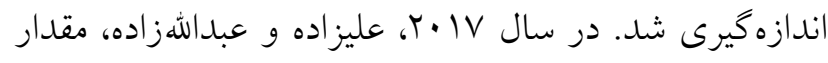

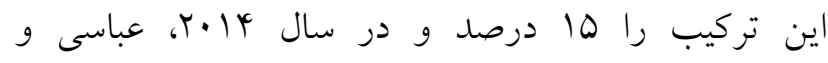

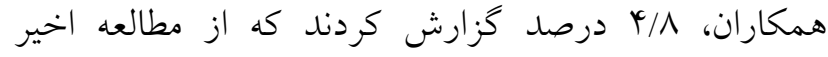
كمتر است. مقدار اين تركيب در مطالعات قبلى بر روى

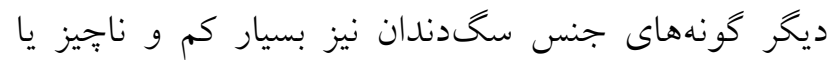
اصلاً كزارش نشده است.

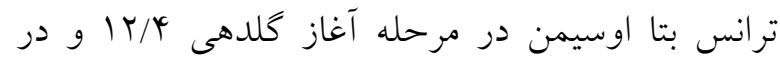

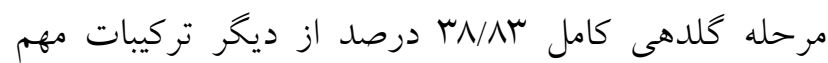

اخرجهه بازده اسانس در مرحله بذردهى از مرحله رويشى

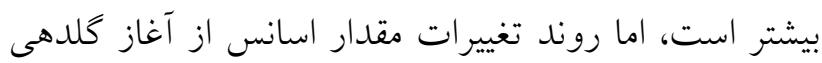

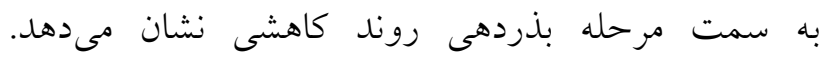

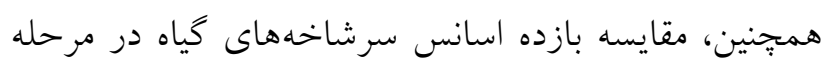

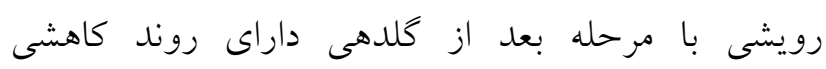

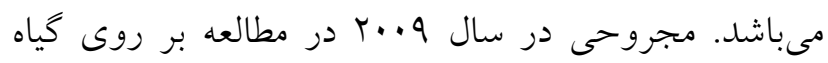

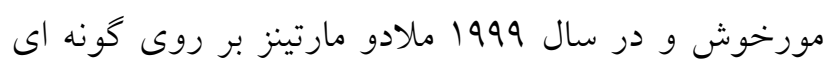

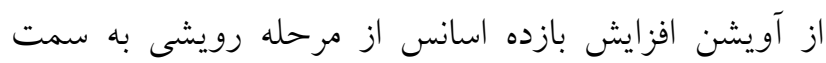

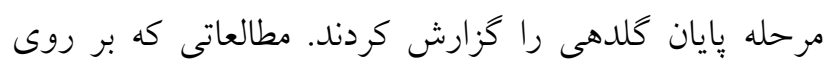

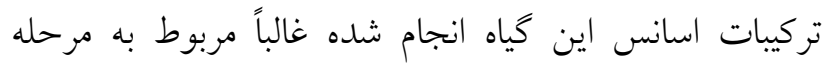

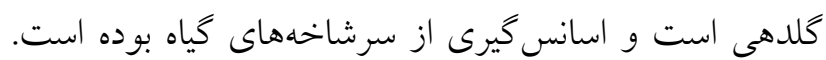

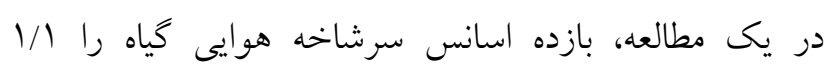

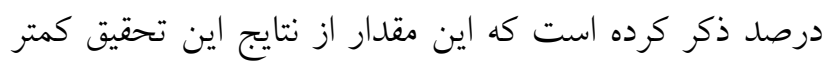

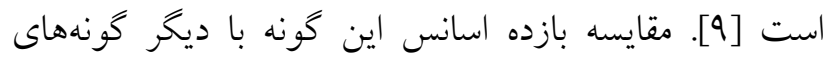

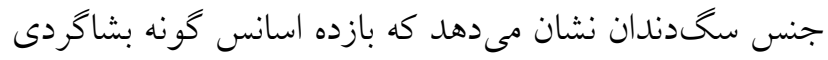

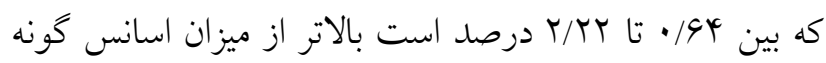

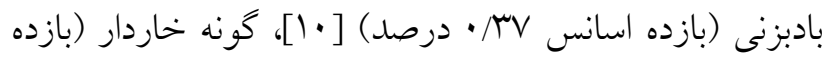

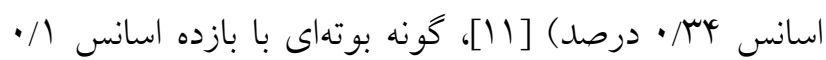

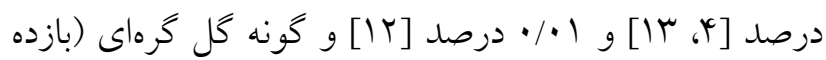

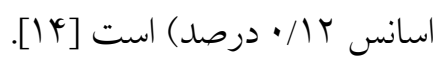

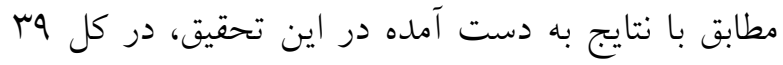

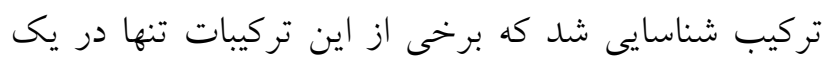

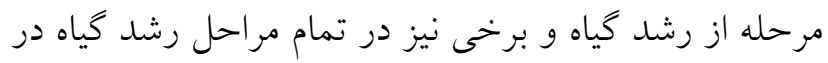

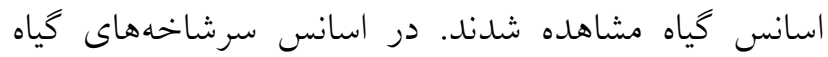

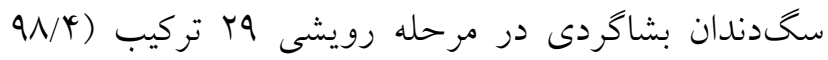

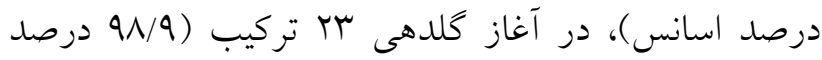

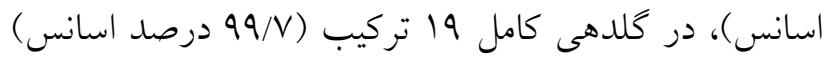
و در مرحله بذردهى نيز 19 تركيب (99 درصد اسانس) برديب)

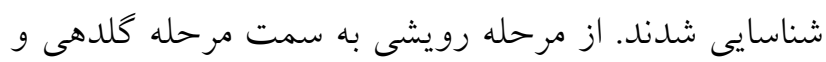

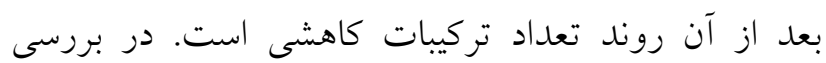


q ب تركيب شناسايى شد. مقايسه تركيبات عمده اسانس از

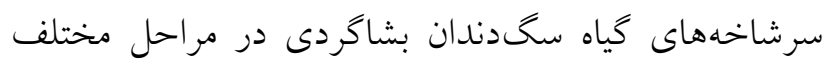

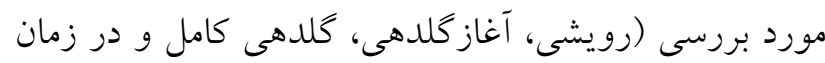

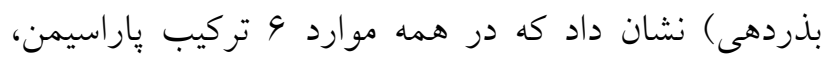

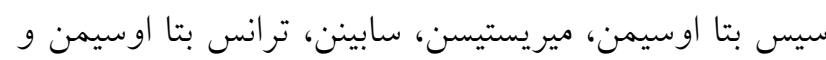
ايزوميريستسن از جمله تركيبات اصلى مى باشند.

\section{مشاركت نويسند}

نويسنده اول: اجراى تحقيق و نغارش اوليه مقاله،

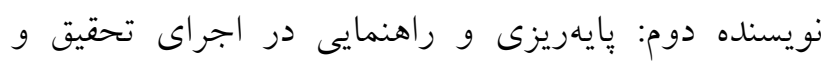

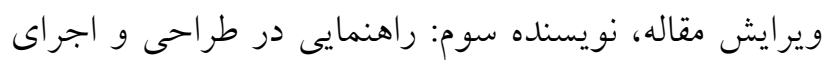

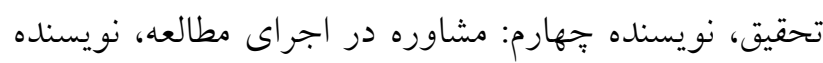
ينجم: مشاوره و انجام آناليز آمارى دادهها.

تضاد منافع هيج گونه تضاد منافعى بين نويسندكان اين مقاله وجود ندارد.

تقدير و تشكر از معاونت آموزشى و يزوهشى دانشخاه علم و هنر يزد جهت مساعدت در انجام اين تحقيق تشكر و قدردانى مى ونى

$$
\text { شود. }
$$

1. Mozaffarian V. New species and new plant records from lran. Iranian Journal of Botany 1985; 3(1): 81-6.

2. Anwar F, Ali M, Hussain, AI and Shahid M. Antioxidant and antimicrobial activities of essential oil and extracts of fennel
اسانس كونه سخدندان بشاكردى است. اين تركيب و سيس

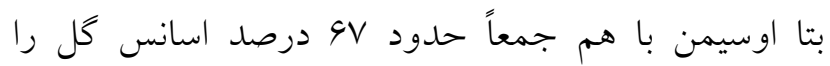

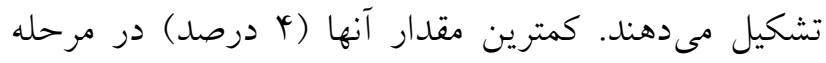

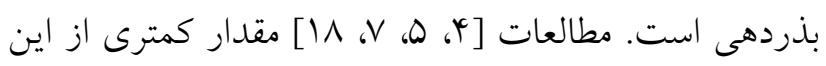

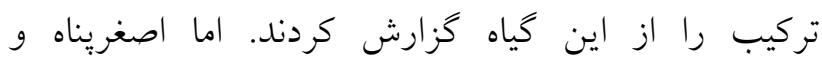

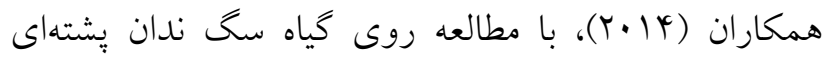

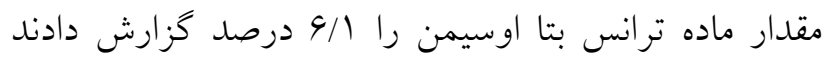

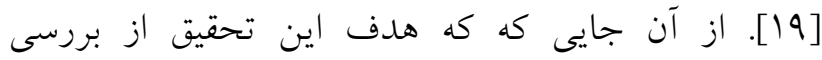

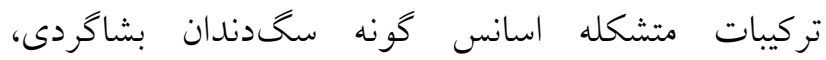

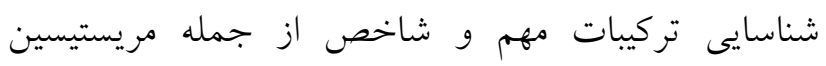

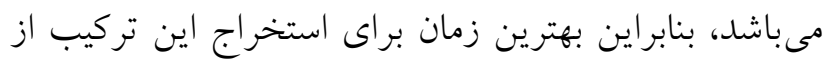

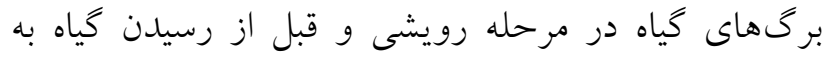

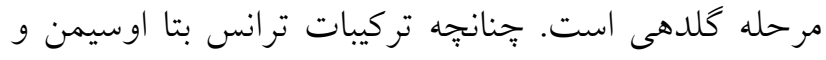

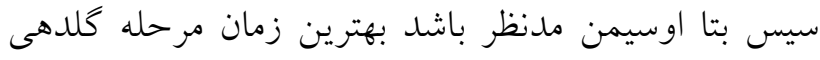

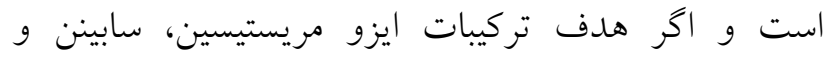
پاراسيمن باشد، بهترين فصل نمونه بردارى از كياه مرحله بذردهى است.

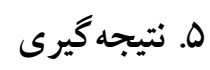

به طور كلى، نتايج اين تحقيق نشان داد كه بيشترين

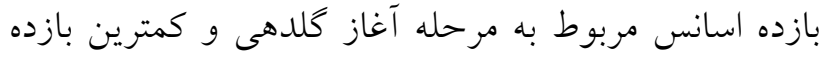
اسانس مربوط به مرحله رويشى مىباشد. هم:تخنين نتايج

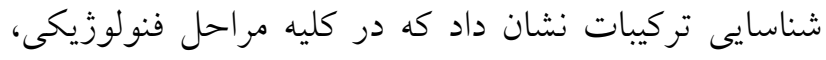

(Foeniculum vulgare Mill.) seeds from Pakistan. Flavour Fragr J. 2009; 24(4): 170-6. 3. Hafezian M, Asgarpanah J and Rahimifard N. Chemical composition and antimicrobial activity of the essential oil from the endemic species Pycnocycla bashagardiana Mozaff. 
Latin American Journal of Pharmacy. 2016; 35(7): 1634-9.

4. Alizadeh $\mathrm{A}$ and Abdollahzadeh $\mathrm{H}$. Essential oil constituents and antimicrobial activity of Pycnocycla bashagardiana Mozaff. from Iran. Natural Product Research. 2017; 31(17): 2081-4.

5. Nasrollahi I, Farjam M, Talebi E, Khosravinezhad $M$ and Shivkumar. AntiMicrobial and Antioxidant Activity of Different Pycnocycla bashagardiana Essential Oil. International Journal of Research Studies in Biosciences 2017; 5(4): 15-21.

6. Nasr $M$ and Asgarpanah J. Volatile Constituents of the Seeds and Fruit of Pycnocycla nodiflora. Natural Product Communications 2014; 9(12): 1781-2.

7. Majrouhi AA. Chemical composition of the leaf essential oil of Zhumeria majdae growing in South Iran. Chemistry of Natural Compounds 2009; 45(3): 429-30.

8. Molado-Martinos M, Bernaldo-Gil MG, Beirao ML and Rouzet M. Seasonal variation and composition of Thymus zygis essential oil. Flavour and Fragrance Journal. 1999; 14(3): 177-82.

9. Abbasi E, Ghorbandadras $\mathrm{O}$ and Asgarpanah J. Essential oil composition of the endemic species Pycnocycla bashagardiana Mozaff. Journal of Essential Oil Res. 2014; 26: 363-6.

10. Yari M, Aghjani Z, Masoudi S, Monfared $A$ and Rustaiyan A. Essential oils of Pycnocycla flabellifolia (Boiss.) and Malabai lasecacule (Miller) Boiss from Iran. DARU Journal of Pharmaceutical Sciences 1999; 7(3): 1-3.

11. Ahmadi L and Mirza M. Volatile constituents of the essential oil of Pycnocycla spinose Decne and Boiss from Iran. $J$. Essential Oil Res. 1998; 10(2): 197-8.

12. Javidnia $K$, Mir $R$, Soltani $M$ and Khosravi AR. Constituents of the essential oil of Pycnocycla nodiflora Decne. ex Boiss. from Iran. J. Essential Oil Res. 2008; 20: 502-4.

13. Alimirzalou $F$ and Asgarpanah J. Chemical composition of the volatile oils from the fruits and seeds of the medicinal plant Pycnocycla aucherana from Iran. Farmacia 2017; 65(4): 591-4.

14. Teimouri MB, Shaabani A and Sefidkon F. Composition of the essential oils of Pycnocycla aucherana Decne. ex Boiss. var. aucherana and Pycnocycla musiformis Hedge et Lamond from Iran. J. Essential Oil Res. 2005; 17(5): 473-4.

15. Jahandar F, Asgarpanah J, Najafizadeh $P$ and Mousavi Z. Anti-inflammatory activity and chemical composition of Pycnocycla bashagardiana fruits essential oil in animal models. Iranian J. Basic Medical Sciences 2018; 21(2): 188-93.

16. Asghari GHR, Houshfar GHA and Mahmoudi Z. Composition of the essential oil of Pycnocycla Spinosa Decne. ex. Boiss from Isfahan. DARU Journal of Pharmaceutical Sciences 2001; 9(3 - 4): 28-9.

17. Akhgar MR, Khodashenas M and SalariDehshikh H. Chemical constituents from the flower and leaf essential oils of Pycnocycla musiformis. Trends in Modern Chemistry 2012; 4(1): 6-9.

18. Jahandar $F$, Asgarpanah $J$, Najafizadeh $P$ and Mousavi Z. Anti-inflammatory activity and chemical composition of Pycnocycla bashagardiana fruits essential oil in animal models. Iran. J. Basic Med. Sci. 2018; 21(2): 188-93. 
19. Asgarpanah J, Karbalaei Nand Behbahani P. Essential oil composition of the endemic species of Pycnocycla caespitosa Boiss and Hausskn. J. Essential Oil-bearing Plants JEOP. 2014; 17(4): 633-7.
How to cite this article: Abdolsamadi A, Meftahizadeh H, Vazifeshenas MR, Soltanipour MA, Ghorbanpour M. Comparison of essential oil content and constituents in Pycnocycla bashgardiana Mozaffarian during different phenological stages. Journal of Medicinal Plants 2020; 19(75): 154-167.

doi: 10.29252/jmp.19.75.154 
Journal of Medicinal Plants

Institute of

Medicinal Plants

Journal homepage: $\underline{w w w . j m p . i r}$

Research Article

Comparison of essential oil content and constituents in Pycnocycla bashgardiana Mozaffarian during different phenological stages

\section{Adel Abdolsamadi' ${ }^{1}$, Heidar Meftahizadeh ${ }^{2, *}$, Mohammad Reza Vazifeshenas ${ }^{3}$, Mohammad Amin Soltanipour ${ }^{4}$, Mansour Ghorbanpour ${ }^{5}$}

${ }^{1}$ Graduate Student (MSc) Department of Medicinal Plants, University of Science and Art, Yazd, Iran

${ }^{2}$ Department of Horticultural Sciences, Faculty of Agriculture \& Natural Resources, Ardakan University, Ardakan, Iran, and Faculty of Medicinal and Industrial Plants Research Institute, Ardakan University, Ardakan, Iran

${ }^{3}$ Faculty member of Agriculture and Natural Resources Research Center of Yazd, Agricultural and Research Education and Extension Organization (AREEO) Yazd, Iran

${ }^{4}$ Agricultural and Natural Resources Research Center, Hormozgan, Hormozgan, Iran

${ }^{5}$ Department of Medicinal Plants, Faculty of Agriculture and Natural Resources, Arak University, Arak, Iran

\begin{tabular}{|c|c|}
\hline ARTICLE INFO & ABSTRACT \\
\hline $\begin{array}{l}\text { Keywords: } \\
\text { Pycnocycla bashgardiana } \\
\text { Mozaffarian } \\
\text { Endemic } \\
\text { Flowering, GC/MS } \\
\text { Hormozgan } \\
\text { Meristecine }\end{array}$ & $\begin{array}{l}\text { Backround: The Pycnocycla bashgardiana Mozaffarian is one of the endemic } \\
\text { medicinal species in Hormozgan province. Because of the valuable compound } \\
\text { myristicin in the organs of this plant, it is used intravenously in the treatment of } \\
\text { some diseases. Objective: Evaluation of essential oil content and constituents of } \\
\text { aerial parts during different phenological stages including before flowering, } \\
\text { flower initiation, full flowering and seed maturity stsgegs. Methods: the essential } \\
\text { oil was isolated using Clevenger-type apparatus, and their constituents were } \\
\text { identified using GC and GC/MS devices. Results: The highest essential oil } \\
\text { content ( } 2.22 \%) \text { was related to flower initiation stage. The essential oil content at } \\
\text { pre-flowering, full flowering and seed maturity stages were } 0.64 \% \text {, } 1.54 \% \text { and } \\
0.74 \% \text {, respectively. In general, } 39 \text { compounds were identified in the isolated } \\
\text { essential oil, some of which were found only in one stage of growth and some } \\
\text { others were observed in all of the four examined stages. Comparison of essential } \\
\text { oil constituents showed that in all stages, p-cymene, E-beta-ocimene, myristecine, } \\
\text { sabinene, (Z) -beta-ocimene and isomyristicin were the major compounds. The } \\
\text { myristecine level in all stages was one of the three high compounds that reached } \\
\text { to 52.71, 12.8\%, 8.6\% and } 17 \% \text { at before flowering, flower initiation, full } \\
\text { flowering and seed maturity stages, respectively. Conclusion: According to the } \\
\text { results, the maximum amount of myristecine was obtained at the vegetative stage } \\
\text { before the plant reaches flowering. Also, the maximum content of Z-beta-ocimine } \\
\text { and E-beta-ocimine compounds were found during flowering, however, maximum } \\
\text { iso-myristicin, subabinen, and parasimine were observed at seed maturity stage. }\end{array}$ \\
\hline
\end{tabular}

Abbreviations: GC, gas chromatography; GC/MS, gas chromatography/mass spectroscopy

* Corresponding author: hmeftahizade@ardakan.ac.ir

doi: $10.29252 /$ jmp. 19.75 .154

Received 14 September 2019; Received in revised form 26 November 2019; Accepted 16 December 2019

(C) 2020. Open access. This article is distributed under the terms of the Creative Commons Attribution-NonCommercial 4.0 International License (https://creativecommons.org/licenses/by-nc/4.0/) 